\title{
Adubação nitrogenada associada ao gel hidroretentor na produção e crescimento do tomateiro de mesa
}

\author{
Fábio José Carvalho ${ }^{1}$, Lorena Braz Carneiro ${ }^{1}$, Leticia Silva e Carvalho ${ }^{1}$, Lucas Luís Faustino ${ }^{1}$, Emerson \\ Trogello ${ }^{1}$ \\ ${ }^{1}$ Instituto Federal de Educação Ciência e Tecnologia Goiano - IFGoiano, Campus Morrinhos, GO. E-mail: \\ lucas.faustino@uenf.br
}

\section{Resumo}

Objetivou-se avaliar a associação do uso de hidrogel e utilização da adubação nitrogenada na cultura do tomateiro de mesa. Foi conduzido um experimento, no Instituto Federal Goiano - Campus Morrinhos. As plantas foram conduzidas verticalmente utilizando-se fitilhos como suporte e mantendo-se oito cachos por planta. O delineamento experimental adotado foi o de blocos com os tratamentos ao acaso, com quatro repetições. Os tratamentos foram dispostos em parcelas subdivididas duas aplicações (com e sem gel hidroretentor) e quatro adubações nitrogenadas (0;180; 360 e $540 \mathrm{~kg} \mathrm{ha}^{-1}$ ). As adubações de cobertura foram realizadas aos 25; 40; 55; 70; 85; 100 e 115 dias após o transplantio das mudas, respectivamente. Verificou-se que a fonte de variação hidrogel ocorreu efeito significativos, no diâmetro do caule final, matéria verde e textura do fruto. Para o fator doses de nitrogênio, os resultados apontam incrementos nas características clorofila na região basal, média e apical da planta, diâmetro do caule final, matéria seca e verde, número de frutos médios, peso por quilograma de frutos médios na área útil, taxa de crescimento absoluto par altura da planta e produtividade por hectare. A aplicação do gel hidroretentor não influenciou na produção do tomateiro de mesa cv. Santy.

Palavras-chave: Solanum lycopersicum L; clorofila; doses de nitrogênio; pós colheita tomateiro.

\section{Nitrogen fertilization associated with the hydroretting gel in the production and growth of the table tomato}

\begin{abstract}
The objective of this study was to evaluate the association between hydrogel use and nitrogen fertilization in tomato crop. An experiment was conducted at the Federal Institute Goiano - Campus Morrinhos. The plants were conducted vertically using strips for support and maintaining eight bunches per plant. The experimental design was a randomized complete block design with four replications. The treatments were arranged in split plots, two applications (with and without hydrochloridating gel) and four nitrogen fertilizers $\left(0 ; 180 ; 360\right.$ and $\left.540 \mathrm{~kg} \mathrm{ha}^{-1}\right)$. Topdressing was performed at 25; 40; 55; 70; 85; 100 and 115 days after seedling transplantation, respectively. It was found that the source of hydrogel variation had significant effect on the final stem diameter, green matter and fruit texture. For the nitrogen dose factor, the results indicate increases in the chlorophyll characteristics in the basal, medium and apical region of the plant, final stem diameter, dry matter and green matter, number of average fruits, weight per kilogram of average fruits in the useful area, rate. of absolute growth for plant height and productivity per hectare
\end{abstract} Keywords: Solanum lycopersicum L; chlorophyll; nitrogen doses; post harvest tomato.

\section{Introdução}

O tomate é uma das culturas mais cosmopolita mundo, sendo uma fonte importante de vitaminas e minerais, seu consumo pode ser in natura ou frescos em saladas ou industrializados sua disponibilidade abrange as diversas classes sociais, contribuindo para uma dieta saudável e bem equilibrada. A classificação 
taxonômica do tomateiro é da família Solanaceae, gênero Solanum, espécie Solanum lycopersicum L (ZEIST et al., 2018).

A cultura do tomateiro necessita de uma atenção especial, pois é uma planta que exige um alto nível tecnológico, investimentos e emprego de mão-de-obra qualificada. Sendo estas exigências atribuídas a crescente urbanização, aumentando a demanda de alimentos. Para o aumento da produção o emprego de novos híbridos, instalação de um sistema de irrigação eficiente, utilização racional de insumos e defensivos agrícolas e a diminuição de perdas pós-colheita, são práticas indispensável para o sucesso da atividade.

Para minimizar perdas e aumentar a disponibilidade de água no solo, o gel hidroretentor apresenta-se como uma alternativa viável e economicamente acessível demonstrando grande eficiência (JAIN et al., 2017; FIDELIS et al., 2018; SINGH et al., 2018). De acordo com Felippe et al. (2016), efeitos benéficos são obtidos no crescimento $e$ desenvolvimento vegetativo das plantas. De modo geral o hidrogel tem grande capacidade de reter e liberar gradativamente água para as plantas, é considerado um produto promissor para a agricultura já que possibilita o desenvolvimento de plantas em áreas com baixo índice pluviométrico, possibilita uma maior taxa de sobrevivência para as plantas, diminui a número de irrigação (SANCHES, 2013).

Conforme estudos De Mamann et al. (2016), demonstraram que o uso do hidrogel como incremento para eficiência do nitrogênio na planta foi benéfica, sendo que ocorreu um aumento da quantidade de grãos na cultura do trigo. Moreira et al. (2010) observaram que doses excessivas de hidrogel podem ser prejudiciais ao desenvolvimento das mudas, devido ter um ambiente pouco aerado, criando-se assim um microclima favorável ao aparecimento de doenças.

O nitrogênio ( $\mathrm{N})$ é o elemento mais requerido pelas plantas, sendo responsável pelo seu desenvolvimento vegetativo e reprodutivo. As plantas usam duas formas de absorção do nitrogênio, a forma nítrica (NO3-) e a amoniacal $\left(\mathrm{NH}_{4}{ }^{+}\right)$. O tomateiro necessita de níveis específicos de adubação nitrogenada, pois a planta é favorecida com aumento de matéria seca, diâmetro do caule, florescimento, frutificação e produtividade. A falta de uma adubação nitrogenada adequada, traz problemas para o desenvolvimento da planta, reduz o crescimento da parte aérea e consequentemente reduz a taxa fotossintética implicando na produtividade final dos frutos (ALMEIDA, 2011).

A utilização adequada de insumos requeridos pela cultura do tomateiro contribui de forma expressiva para seu desenvolvimento. Alguns aspectos relevantes devem ser observados, como a obtenção de fontes nitrogenadas que proporcionem ao produtor maior rendimento econômico (PORTO et al., 2014).

Considerando as informações supracitadas, o objetivo foi avaliar doses de nitrogênio associado com ao uso do gel hidroretentor na produção e qualidade do fruto do tomateiro híbrido.

\section{Material e Métodos}

O experimento foi conduzido na área experimental do Instituto Federal Goiano Campus Morrinhos Rodovia BR-153, Km 633, Zona Rural. A cidade de Morrinhos abrange a área compreendida entre as coordenadas de $17^{\circ}$ a $18^{\circ}$ de latitude sul e $48^{\circ}$ a $49^{\circ}$ de longitude oeste. A região apresenta um clima Aw e precipitação média anual de $1346 \mathrm{~mm}$, segundo a classificação de Köppen-Geiger.

Foram coletadas amostras de solo da área na profundidade de $0-0,20 \mathrm{~m}$ da área, cujo experimento foi conduzido. O preparo da área e do solo foi iniciado um mês antes da instalação do experimento, com a eliminação da vegetação espontânea existente no local. A semeadura foi realizada em 18 de fevereiro de 2016, em bandejas de poliestireno com 200 células. $O$ transplantio foi realizado no dia 10 de março de 2016, com as mudas medindo $15 \mathrm{~cm}$ de altura e 4 folhas definitivas. Foi empregado o espaçamento $1,2 \mathrm{~m}$ entre linhas e 0,7 m entre plantas.

A análise de solo na área experimental apresentou a seguinte composição química: $\mathrm{pH}$ 5,3; $\left(\mathrm{CaCl}_{2}\right)=5,1 ; \mathrm{H}+\mathrm{Al}=1,6 \mathrm{cmol}_{\mathrm{c}} \mathrm{dm}^{-3} ; \mathrm{Ca}=1,7$ $\mathrm{cmol}_{\mathrm{C}} \mathrm{dm}^{-3} ; \mathrm{Mg}=0,5 \mathrm{cmol}_{\mathrm{c}} \mathrm{dm}^{-3} ; \mathrm{P}$ (resina) $=14 \mathrm{mg}$ $\mathrm{dm}^{-3} ; \mathrm{K}=0,29 \mathrm{cmol}_{\mathrm{c}} \mathrm{dm}^{-3}$; Matéria orgânica $=26 \mathrm{~g}$ $\mathrm{dm}^{-3} ; \mathrm{CTC}=4,1 \mathrm{cmolc} \mathrm{dm}^{-3} ; \mathrm{V} \%=60,9 ; \mathrm{Cu}=1,0 \mathrm{mg}$ $\mathrm{dm}^{-3}, \mathrm{Fe}=57 \mathrm{mg} \mathrm{dm}^{-3}, \mathrm{Mn}=2,9 \mathrm{mg} \mathrm{dm}^{-3}, \mathrm{Zn}=0,3$

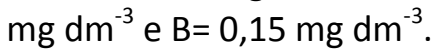

$$
O \text { delineamento experimental foi em }
$$

blocos com os tratamentos ao acaso, em esquema fatorial $2 \times 4$, sendo duas aplicações (com e sem gel hidroretentor) e quatro níveis de adubação nitrogenada, tendo 10 plantas por parcela sendo cada parcela subdividida. Os níveis 
de adubação recomendados para o trabalho foram quatro dosagens de nitrogênio $(0 ; 50 ; 100$ e $150 \%$ ) equivalentes a $\left(0 ; 180 ; 360\right.$ e $\left.540 \mathrm{~kg} \mathrm{ha}^{-1}\right)$ da quantidade total requerida pela cultura obtida pela análise de solo.

O híbrido utilizado foi tomate Santy do tipo mesa cultivado em campo, que possui alta tolerância a rachaduras e manchas, tendo alta adaptação a plantios em épocas de chuva e seca, grande padronização de frutos da base ao ponteiro, frutos firmes, as plantas vigorosas, resistentes a doenças do Vírus do Mosaico do Tomateiro (ToMV), Fusarium raça 1 e 2 e também aos nematoides das galhas ( $\mathrm{Mj}, \mathrm{Mi})$.

Após a interpretação da análise de solos foi realizada a recomendação de adubação conforme Ribeiro et al. (1999). As quantidades e fontes utilizadas para a adubação de plantio foram respectivamente, $400 \mathrm{~kg} \mathrm{ha}^{-1}$ de nitrogênio ( $45 \%$ de N); $500 \mathrm{~kg} \mathrm{ha}^{-1}$ de fósforo (Super Triplo $45 \%$ de $\mathrm{P}_{2} \mathrm{O}_{5}$ com $14 \%$ de $\mathrm{Ca}$ ) e $800 \mathrm{Kg} \mathrm{ha}^{-1}$ de potássio ( $58 \%$ de $\mathrm{K}_{2} \mathrm{O}$ ). A adubação de base para o nitrogênio representou $10 \%$ da dose recomendada para cada tratamento, sendo que estes foram determinados desconsiderando a quantidade aplicada na adubação de base $(40 \mathrm{~kg}$ ha $^{-1}$ ) onde o tratamento 1 não recebeu adubação $\left(0,0 \mathrm{~kg} \mathrm{ha}^{-1}\right)$, o tratamento 2 representa $50 \%$ da dose recomendada (180 $\left.\mathrm{kg} \mathrm{ha}^{-1}\right)$, o tratamento 3 representa $100 \%$ da dose recomendada $(360 \mathrm{~kg}$ $\mathrm{ha}^{-1}$ ) e o tratamento 4 representa $150 \%$ da dose recomendada (540 $\left.\mathrm{kg} \mathrm{ha}^{-1}\right)$, a adubação do fósforo $70 \%$ foi no plantio e $30 \%$ na primeira cobertura, para o potássio foi semelhante ao nitrogênio diferindo nos valores pois a quantidade de potássio requerido foi maior.

A proporção a ser utilizada do gel hidroretentor foi de $4 \mathrm{~g}$ por litro de água, sendo utilizados $400 \mathrm{ml}$ de gel hidroretentor por planta, o gel foi incorporado no sulco de plantio e misturado ao solo.

As avaliações tanto de crescimento, desenvolvimento e produção do tomateiro foram realizadas após o transplantio das mudas, as avaliações realizadas foram:

Altura média de plantas em $(\mathrm{cm})$ : médias das alturas de 6 plantas/parcela, aos 15, 30, 45 e 60 dias após o transplantio e no final;

Diâmetro médio do caule em $(\mathrm{mm})$ : médias dos diâmetros do caule de 6 plantas/parcela, aos $15,30,45$ e 60 dias após o transplantio e no final;

Taxa de crescimento absoluto (TCA) para altura de plantas em $(\mathrm{cm})$, entre os intervalos de avaliações, conforme apresentado por Benincasa, (2003), em que:

$$
T C A=\frac{(A 2-A 1)}{(T 2-T 1)}
$$

$T C A=$ taxa de crescimento absoluto;

A2 e $A 1$ = altura da planta de duas amostragens sucessivas; e

$T 2$ e $T 1$ = intervalos de amostragens.

Número médio de flores: média do número de flores de 6 plantas parcela ${ }^{-1}$ em intervalos de 15 dias;

Matéria verde e seca de brotos laterais em (g): médias da matéria seca dos brotos de 6 plantas parcela ${ }^{-1}$, em intervalos de 15 dias;

Número médio de frutos (média - md): número de frutos de todas as plantas úteis da parcela, em cada tratamento;

Produtividade média, em (Kg ha $\left.{ }^{-1}\right)$;

Distribuição dos frutos por tamanho em $(\mathrm{mm})$ : os frutos foram classificados, conforme normas em vigor no Ministério da Agricultura, de acordo com seu diâmetro em: gigante (maior que $100 \mathrm{~mm}$ ), grande (80-100 $\mathrm{mm})$, médio $(65-80 \mathrm{~mm})$, pequeno (50-65 $\mathrm{mm}$ ) (Codapar, 1995);

Peso dos frutos de acordo com o tamanho: gigante (maior que $100 \mathrm{~mm})$, grande (80-100 $\mathrm{mm})$, médio $(65-80 \mathrm{~mm})$, pequeno $(50-65$ $\mathrm{mm})$;

Acidez total titulável (ATT): determinada por titulação com soluções de $\mathrm{NaOH}(0,05 \mathrm{~N})$ de $10 \mathrm{ml}$ de suco puro obtido após liquidificação de três frutos totalmente maduros;

Teor de sólidos solúveis totais (SST) em ( ${ }^{\circ}$ Brix): determinado transferindo-se uma gota, que deve ser homogeneizada completamente, do suco da fruta para o prisma de um refratômetro manual e em seguida faz-se a leitura do valor obtido;

Relação SST/ATT (Índice de maturação - IM); $\mathrm{pH}$ : determinou-se com o auxílio de um pHmetro. Primeiro é feita uma homogeneização da polpa do tomate depois retira-se o medidor de $\mathrm{pH}$ da solução protetora, lavando-a com água destilada e enxuga para retirar o excesso de água e em seguida inseri o medidor na mistura deixando-o imerso pelo menos $4 \mathrm{~cm}$. Espera até que $\mathrm{o} \mathrm{pH}$ do visor parasse de piscar e realizou-se a leitura.

As plantas foram conduzidas por meio de estaquia vertical, realizando-se quinzenalmente, amarrio e desbrota (ZEIST et al., 2017), com duas hastes por planta. 
A colheita dos frutos foi realizada de forma manual, a partir dos 72 dias após o transplantio (DAT). Para avaliação foram utilizados somente os frutos das plantas úteis das parcelas. Após a colheita, os frutos foram acondicionados em caixas plásticas de $20 \mathrm{~kg}$, identificadas com a respectiva parcela de onde foi colhida, e transportada no mesmo dia para o laboratório, onde foram avaliados.

A análise estatística foi realizada usando o programa "Assistat", sendo a comparação via teste $F$ ao nível de $p<0,05$. Observando-se diferença significativas as médias do fator qualitativo (uso de hidrogel), foram comparadas pelo teste Tukey $(p<0,05)$ e os valores referentes a adubação nitrogenada foram comparados pelo método de regressão polinomial.

\section{Resultados e Discussão}

O presente trabalho não demonstrou efeitos significativos da interação entre a utilização do tratamento hidrogel e as doses de $\mathrm{N}$ para nenhuma das características analisadas. Assim, os resultados foram apresentados separadamente, ou seja, em função das doses de $\mathrm{N}$ e em relação à aplicação ou não do hidrogel.

Pelo resumo da análise de variância dos tratamentos avaliados, observa-se que o efeito significativo para o tratamento hidrogel foi observado apenas para diâmetro do caule final e matéria verde (Tabela 1). Por outro lado, foi observado efeito significativo das doses de nitrogênio para as características clorofila da região basal, clorofila da região mediana e clorofila da região apical da planta, diâmetro do caule final, taxa de crescimento absoluto para altura de plantas, matéria verde e matéria seca das plantas.

Tabela 1. Resumo da análise de variância e comparação de médias para o fator de variação hidrogel, de plantas de tomateiro cv. Santy para as características analisadas altura da primeira inflorescência (APIF), altura final da planta (AFP), clorofila da região basal da planta (CLOrb), clorofila da região mediana da planta (CLOrm), clorofila da região apical da planta (CLOra), diâmetro do caule final (DC), Taxa de crescimento absoluto da altura da planta (TCAap), matéria verde (MVbl) e matéria seca (MSbl).

\begin{tabular}{llllllllll}
\hline FV & APIF $(\mathrm{cm})$ & $\begin{array}{l}\text { AFP } \\
(\mathrm{cm})\end{array}$ & CLOrb & CLOrm & CLOra & $\begin{array}{c}\text { DC } \\
(\mathrm{mm})\end{array}$ & $\begin{array}{c}\text { TCAap } \\
(\mathrm{cm})\end{array}$ & $\begin{array}{c}\text { MVbl } \\
(\mathrm{g})\end{array}$ & $\begin{array}{c}\text { MSbl } \\
(\mathrm{g})\end{array}$ \\
\hline Hidrogel & $0,008^{\text {ns }}$ & $0,66^{\text {ns }}$ & $8,267^{\text {ns }}$ & $0,068^{\text {ns }}$ & $1,12^{\text {ns }}$ & $23,03^{*}$ & $0,01^{\text {ns }}$ & $46,70^{* *}$ & $5,20^{\text {ns }}$ \\
Doses & $1,38^{\text {ns }}$ & $1,59^{\text {ns }}$ & $5,64^{* *}$ & $3,30^{* *}$ & $3,30^{*}$ & $8,26^{* *}$ & $9,22^{* *}$ & $7,14^{* *}$ & $5,87^{* *}$ \\
IN(AXB) & $1,36^{\text {ns }}$ & $0,58^{\text {ns }}$ & $0,95^{\text {ns }}$ & $2,63^{\text {ns }}$ & $0,81^{\text {ns }}$ & $1,77^{\text {ns }}$ & $0,55^{\text {ns }}$ & $0,38^{\text {ns }}$ & $0,97^{\text {ss }}$ \\
CV\% (A) & 8,68 & 4,98 & 1,75 & 3,58 & 3,04 & 3,21 & 8,32 & 21,61 & 27,97 \\
CV\% (B) & 10,36 & 4,37 & 4,73 & 2,90 & 3,04 & 4,26 & 4,95 & 16,77 & 17,74 \\
\hline Sem & 44,00 & 208,25 & 59,38 & 60,68 & 58,73 & $17,79 \mathrm{~b}$ & 2,88 & $417,67 \mathrm{~b}$ & 53,798 \\
Com & 43,87 & 211,25 & 60,45 & 60,88 & 58,06 & $18,79 a$ & 2,89 & 712,78 a & 67,480 \\
\hline Média Geral & 43,93 & 209,75 & 59,92 & 60,78 & 58,40 & 18,29 & 2,88 & 565,22 & 60,63 \\
\hline
\end{tabular}

**Significativo a 0,01 de probabilidade pelo teste $\mathrm{F}$; ${ }^{*}$ Significativo a 0,05 de probabilidade pelo teste $\mathrm{F}$; ${ }^{\text {ns }}$ Não significativo a 0,05 de probabilidade pelo teste $\mathrm{F}$

Esperava-se que o uso do hidrogel proporcionasse uma maior altura da planta, uma vez que o hidrogel, tem a capacidade de absorver, armazenar e liberar uma grande quantidade de água de forma gradativa para as plantas, isto não foi observado no presente trabalho (Tabela 1). Observou-se no entanto, que o uso do hidrogel impactou positivamente no diâmetro de caule, e na matéria verde calculada, tendo incremento de 5,62 e $70,66 \%$ respectivamente. Este resultado pode impactar em uma planta mais robusta e vigorosa quando do uso do hidrogel no ato do transplantio.

Com relação a adubação nitrogenada, podemos observar que o emprego da dose de $327,7 \mathrm{~kg} \mathrm{ha}^{-1}$ de $\mathrm{N}$, dose responsável pela maior leitura feita na região basal da planta, obteve-se um valor SPAD de 62,2 (Figura 1A). Nas demais regiões (mediana e apical), foram obtidos menores valores SPAD respectivamente, sendo 62 na dose de $275,86 \mathrm{~kg} \mathrm{ha}^{-1}$ e 59,46 na dose de $297,7 \mathrm{~kg} \mathrm{ha}^{-1}$ (Figura 1B - 1C). 
Figura 1. Índice SPAD de plantas de tomateiro cv. Santy em função das doses de nitrogênio utilizadas: A região basal; B - região mediana; C - região apical. IFGoiano, Morrinhos-GO.
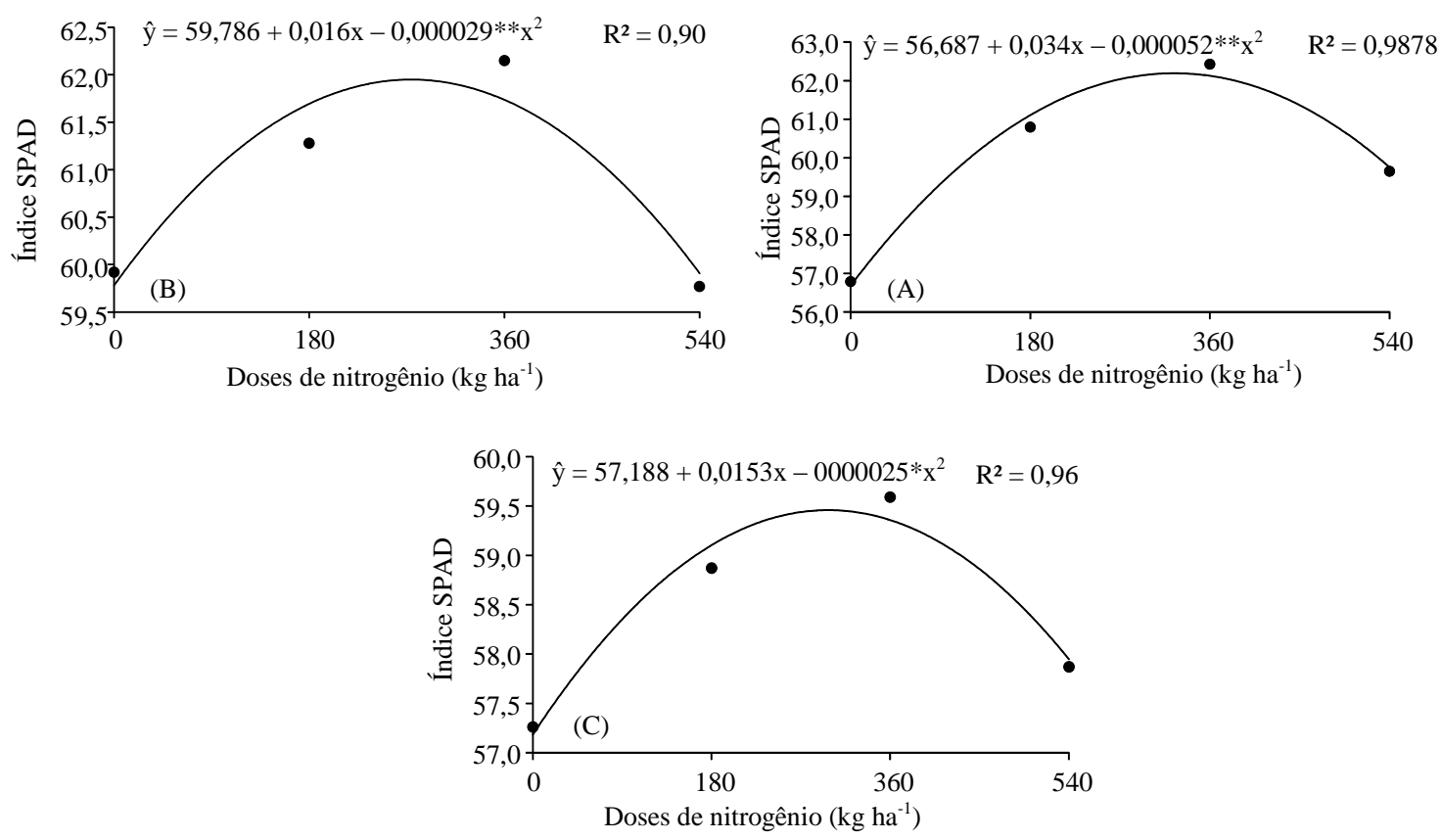

O nitrogênio inorgânico na forma nítrica $\mathrm{NO}_{3}^{-}$ou amoniacal $\mathrm{NH}_{4}^{+}$são absorvidos preferencialmente pelas raízes, possuindo alta mobilidade no solo. A forma nítrica pode ser facilmente lixiviada pelas águas das chuvas e irrigação. De forma geral, ocorre uma correlação positiva entre o teor de nitrogênio e a clorofila, ou seja, havendo um incremento na clorofila com a adição de fertilizantes nitrogenados. Assim, o índice SPAD pode ser utilizado como uma ferramenta para caracterizar o estado nutricional de $\mathrm{N}$ na cultura do tomateiro, de forma rápida e não-destrutiva. Observamos neste trabalho um índice SPAD de 62,2 na região basal do tomateiro. Enquanto Marouelli et al. (2014) obtiveram índice SPAD de 52 para cultivo de tomate de crescimento indeterminado.

Os resultados relativos à diâmetro do caule ao final do ciclo das plantas do tomateiro, cv Santy, obteve-se um ajuste linear da equação, cujo o aumento da dose de nitrogênio proporcionou uma maior espessura do caule observados na (Figura 2A).

Figura 2. Diâmetro do Caule (A), taxa de crescimento absoluto para altura da planta (TCAap) (B), em Função a Doses de Nitrogênio na cultura do tomateiro cv. Santy. IFGoiano, Morrinhos-GO.
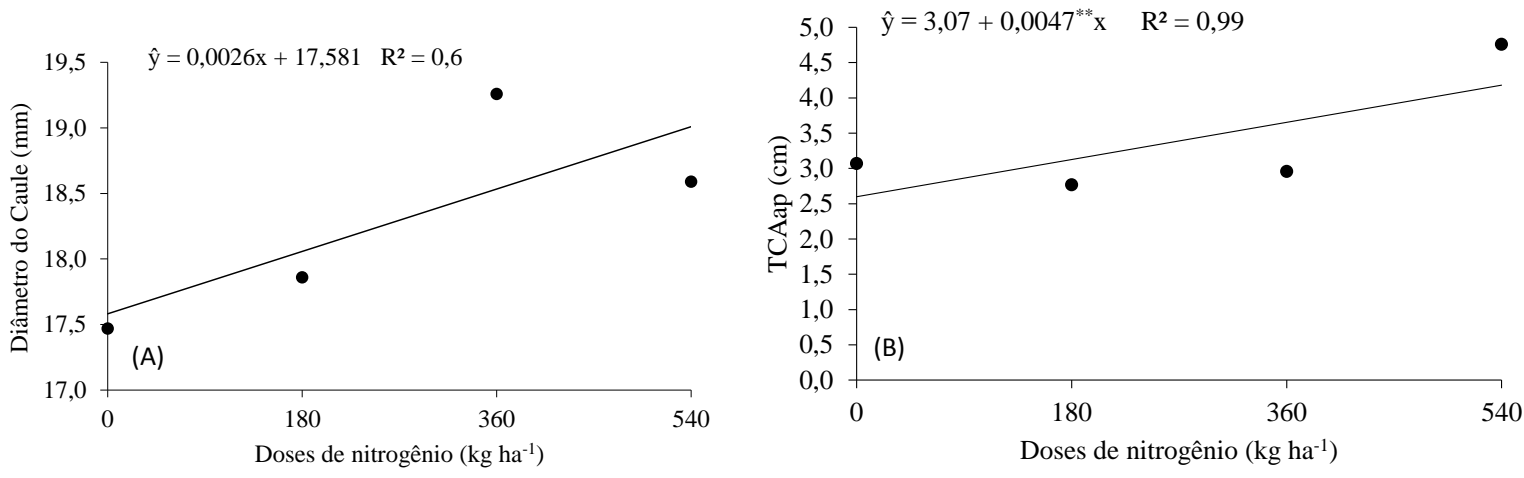
Para se obter um desenvolvimento da planta em nível nutricional adequado, deve-se fazer aplicações de fertilizantes para maximizar o crescimento e desenvolvimento. Em estudos feitos por Porto et al. (2014), observou-se efeitos significativos para o diâmetro do caule, onde foi observado um desenvolvimento expressivo na espessura da haste da planta quando aumentava a dose de nitrogênio, corroborando com o presente trabalho.

O tomate destinado ao consumo in natura consiste num fruto que possui um elevado teor de água em seu interior, no qual estão sujeitos a estresses bióticos e abióticos que podem acelerar a sua degradação. Alguns fatores internos e externos podem, inclusive, contribuir para diminuir a qualidade do fruto. Fatores externos estão relacionados a massa, formato e coloração do fruto, os fatores internos são atributos como a qualidade, acidez, firmeza, textura e compostos nutricionais (Soares et al., 2011). O aparecimento de novas cultivares de mesa do grupo salada, possibilitou um maior tempo de prateleira devido aos avanços no melhoramento genético (NICK; BORÉM, 2016). Demonstrando um comportamento linear (Figura $2 \mathrm{~B})$, os tratamentos que receberam quantidades maiores de $\mathrm{N}$, resultaram em maior crescimento das plantas.
A taxa de crescimento absoluto para altura de planta (TCAap) é usada para expressar a velocidade de crescimento de uma planta, ao longo de um determinado período, sendo considerado um método simples e fácil de ser aplicado se baseando em valores primários sem que haja demanda de equipamentos sofisticado (LOPES et al., 2011; LOPES; LIMA, 2015). Resultados distintos foram observados por Porto et al. (2014) onde foi visto que a taxa de crescimento das plantas teve um decréscimo independentemente das doses de nitrogênio aplicadas em cobertura. Sendo assim a TCAap pode ser usada para se ter ideia da velocidade média de crescimento ao longo do período de observação do desenvolvimento da cultura.

Os estudos de regressão para as variáveis, matéria verde e matéria seca dos brotos laterais da planta em função das doses de nitrogênio são representados nas (Figuras 3A 3B) respectivamente. Foi observado um acumulo de matéria verde na dose máxima de $276 \mathrm{~kg} \mathrm{ha}^{-1}$, demonstrando que o aumento das doses de $\mathrm{N}$, proporcionava um decréscimo na matéria verde. Em relação a matéria seca da mesma forma os tratamentos com doses superiores tiveram um decréscimo nos números de brotos laterais obtendo um menor peso.

Figura 3. Matéria verde dos brotos laterais (A) e matéria seca de brotos laterais (B), cv. Santy em função da dose de nitrogênio. IFGoiano, Morrinhos-GO.

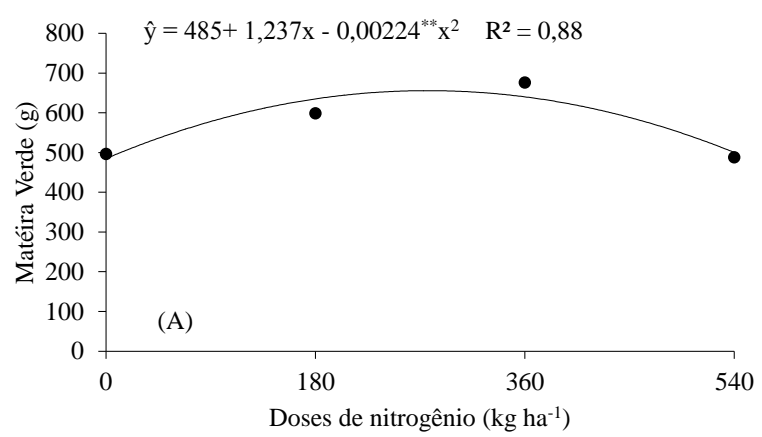

Por meio de estudos de Almeida, (2011), a falta ou excesso de nitrogênio ocasiona alterações fisiológicas nas plantas, contribui na ocorrência de impactos ambientais devido ao acumulo de sais no solo, sendo assim quando aplicada em grande quantidade a planta cria condições favoráveis ao ataque de pragas, por outro lado quando diminui a adubação nitrogenada ocorre uma perda na produtividade.

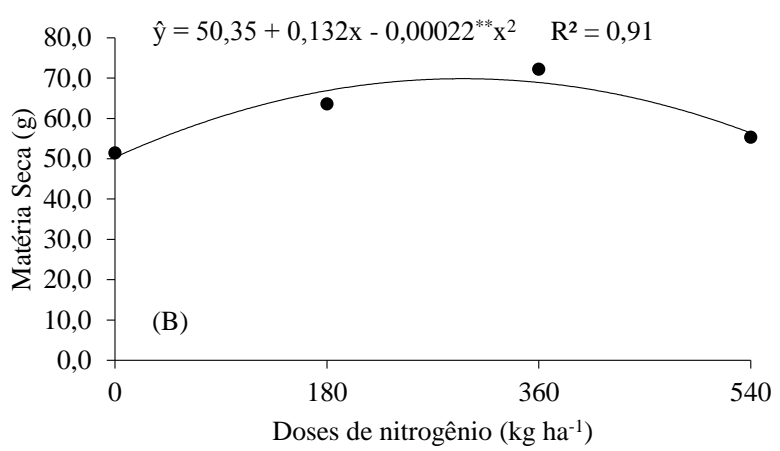

De acordo com Lopes e Lima (2015), o nitrogênio favorece o crescimento vegetativo, o aumento de matéria e expressão do potencial produtivo da cultura. Sua falta pode afetar as fases de formação de órgãos para absorção de nutrientes e fotossíntese, órgãos florais e na translocação e acumulo de assimilados. Trabalhando com doses de nitrogênio, lâminas de irrigação e diferentes coeficientes culturais, Ertek et al. (2012), observaram aumento da área foliar 
de acordo com o aumento da dose de nitrogênio. Já Porto et al. (2014), observaram que fontes nítricas proporcionaram maior acumulo de matéria seca no tomateiro.

O hidrogel não apresentou respostas para nenhuma das características analisadas (Tabela 2 e 3). No entanto para o fator doses de nitrogênio foi influenciada significativamente o número de frutos médios (Tabela 2), valores de produção por quilograma de frutos médios e produção por hectare (Tabela 3).

Tabela 2. Resumo da ANOVA e comparação de medias para o fator de variação hidrogel, de plantas de tomateiro cv. Santy para as características analisadas, Número de frutos pequenos (Nfpeq), Número de frutos médios (Nfmed), Número de frutos grandes (Nfgra), Número de frutos gigantes (Nfgig), número de frutos defeituosos (Nfdef).

\begin{tabular}{cccccc}
\hline FV & Nfpeq & Nfmed & Nfgra & Nfgig & Nfdef \\
\hline Hidrogel & $0,11^{\text {ns }}$ & $6,59^{\text {ns }}$ & $0,02^{\text {ns }}$ & $5,07^{\text {ns }}$ & $2,83^{\text {ns }}$ \\
Doses & $0,57^{\text {ns }}$ & $11,60^{*}$ & $0,55^{\text {ns }}$ & $0,52^{\text {ns }}$ & $0,70^{\text {ns }}$ \\
IN (AXB) & $0,12^{\text {ns }}$ & $0,78^{\text {ns }}$ & $0,15^{\text {ns }}$ & $0,14^{\text {ns }}$ & $0,19^{\text {ns }}$ \\
CV\% (A) & 16,32 & 9,69 & 45,49 & 96,58 & 8,97 \\
CV\% (B) & 22,92 & 19,45 & 53,03 & 115,9 & 42,52 \\
\hline Sem & 27,35 & 15,37 & 7,78 & 0,36 & 3,72 \\
Com & 27,89 & 16,78 & 7,62 & 0,80 & 3,53 \\
\hline Média & 27,62 & 16,07 & 7,7 & 0,58 & 3,62 \\
\hline
\end{tabular}

**Significativo a 0,01 de probabilidade pelo teste $\mathrm{F} ;{ }^{*}$ Significativo a 0,05 de probabilidade pelo teste $\mathrm{F}$; ns. Não significativo a 0,05 de probabilidade pelo teste $F$

Tabela 3. Resumo da ANOVA e comparação de medias para o fator de variação hidrogel, de plantas de tomateiro cv. Santy para as características analisadas, Peso de frutos pequenos na área útil (Pfp), Peso de frutos médios na área útil (Pfmd), Peso de frutos grandes na área útil (Pfgr), Peso de frutos gigantes na área útil (Pfgig), Peso de frutos defeituosos na área útil (Pfdef) e produtividade por hectare (Pr.Ha)

\begin{tabular}{lllllll}
\hline FV & $\begin{array}{l}\text { Pfp } \\
(\mathrm{kg})\end{array}$ & $\begin{array}{l}\text { Pfmd } \\
(\mathrm{kg})\end{array}$ & $\begin{array}{l}\text { Pfgr } \\
(\mathrm{kg})\end{array}$ & $\begin{array}{l}\text { Pfgig } \\
(\mathrm{kg})\end{array}$ & $\begin{array}{l}\text { Pfdef } \\
(\mathrm{kg})\end{array}$ & $\begin{array}{l}\text { Pr.Ha } \\
(\mathrm{kg})\end{array}$ \\
\hline Hidrogel & $0,038^{\mathrm{ns}}$ & $2,19^{\mathrm{ns}}$ & $0,008^{\mathrm{ns}}$ & $5,3^{\mathrm{ns}}$ & $1,06^{\mathrm{ns}}$ & $0,95^{\mathrm{ns}}$ \\
Doses & $0,73^{\text {ns }}$ & $11,05^{*}$ & $0,54^{\text {ns }}$ & $0,52^{\mathrm{ns}}$ & $0,84^{\mathrm{ns}}$ & $2,49^{*}$ \\
IN(AXB) & $0,067^{\mathrm{ns}}$ & $0,59^{\text {ns }}$ & $0,16^{\text {ns }}$ & $0,13^{\text {ns }}$ & $0,18^{\text {ns }}$ & $0,098^{\text {ns }}$ \\
CV\% (A) & 18,01 & 12,71 & 45,21 & 95,23 & 9,2 & 12,86 \\
CV\% (B) & 22,37 & 19,25 & 52,81 & 116,42 & 42,58 & 23,25 \\
\hline Sem & 4,04 & 3,45 & 2,1 & 0,15 & 0,55 & 88724,2 \\
Com & 4,10 & 3,69 & 2,96 & 0,33 & 0,53 & 92323,9 \\
\hline Média & 4,07 & 3,57 & 2,53 & 0,48 & 0,54 & 90523,6
\end{tabular}

**Significativo a 0,01 de probabilidade pelo teste $\mathrm{F} ;{ }^{*}$ Significativo a 0,05 de probabilidade pelo teste $\mathrm{F}$; ns. Não significativo a 0,05 de probabilidade pelo teste $\mathrm{F}$.

$\mathrm{Na}$ cultura da abobrinha "Caserta", Azambuja et al. (2015), observaram resultados semelhantes nos tratamentos submetidos com aplicação ou não de hidrogel (Tabela 2), não impactando no aumento de frutos em suas diferentes classificações.

Quanto a variável número de frutos médios relacionados à dose de nitrogênio (Figura $4 \mathrm{~A})$, observou-se uma regressão polinomial quadrática, que proporcionou um maior número de frutos médios na dose de $258 \mathrm{~kg} \mathrm{ha}^{-1}$.
Resultados encontrados por Nagel e Machado (2011), os quais constataram aumento crescente no número de frutos respondendo significativamente à aplicação de doses de nitrogênio nas cultivares de abobrinhas "Menina Brasileira" e "Piramoita". Efeitos semelhantes das doses de $\mathrm{N}$ sobre o número de frutos foi descrito por Azambuja et al. (2015), na cultura da abobrinha "Caserta".

Os resultados encontrados neste trabalho para números de frutos por planta (20 frutos) são 
similares aos encontrados por Andriolo et al. (2004) e Fandi et al. (2010), que obtiveram produção de 22 e 29 frutos por plantas, respectivamente.

Quanto a produção, em quilograma, de frutos médios, obteve-se o maior valor $(4,4 \mathrm{~kg} \mathrm{~m}$ linear $^{-1}$ ) para a dose de $255 \mathrm{~kg} \mathrm{ha}^{-1}$. Quanto a produtividade da cultura no hectare, observou-se que a dose de nitrogênio de $231,5 \mathrm{~kg} \mathrm{ha}^{-1}$, alcançou produtividades superiores de 102.261 $\mathrm{kg} \mathrm{ha}^{-1}$ de frutos (Figura 4C).

Figura 4. Número de frutos médios (A), peso médio de frutos (B) e produtividade por hectare (C): B cv. Santy em função das doses de nitrogênio. IFGoiano, Morrinhos-GO.
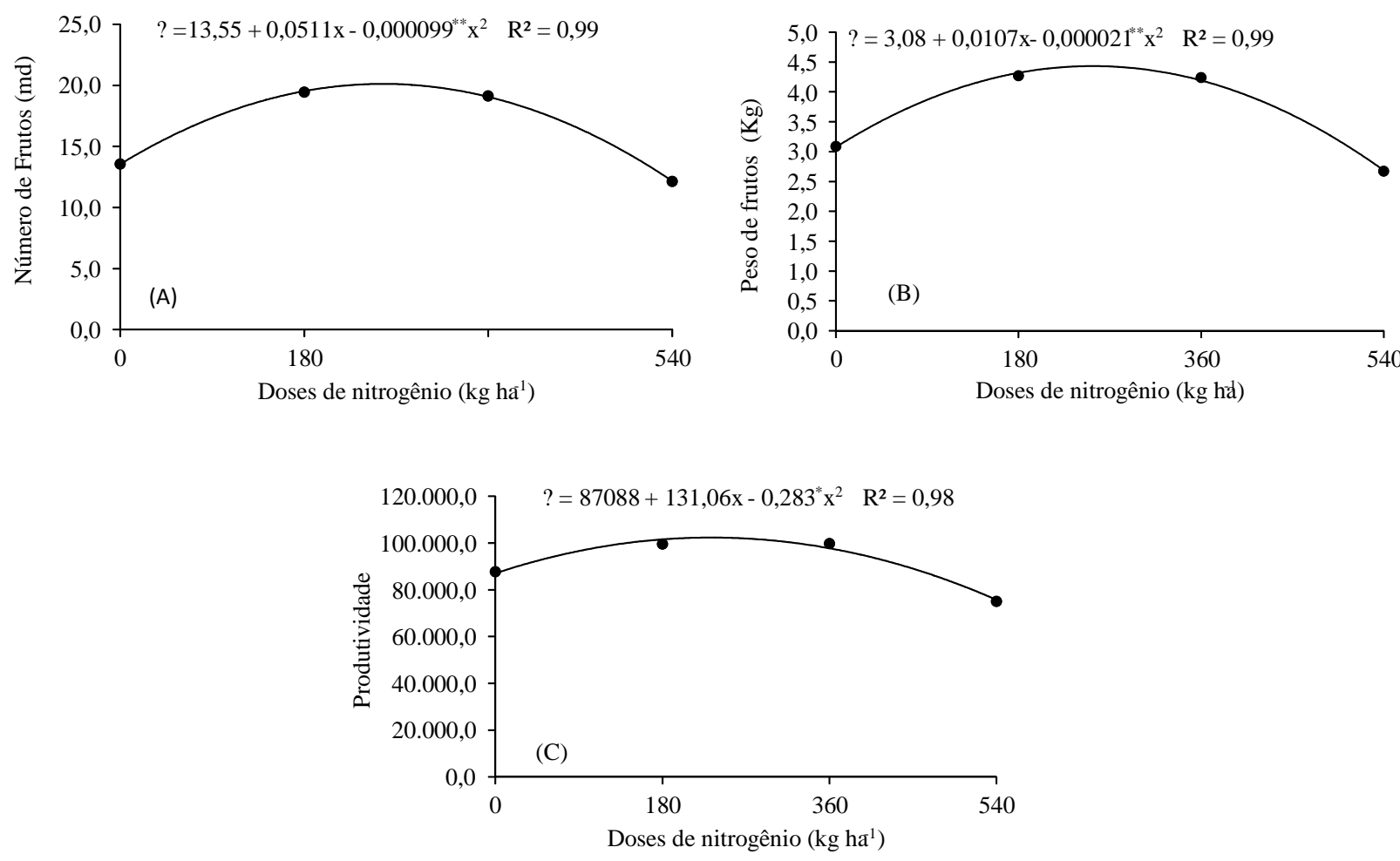

Os efeitos das doses de nitrogênio foram significativos para peso de frutos médios e produtividade por hectare, foi visto que ocorreu uma regressão polinomial quadrática expressiva para ambas as variáveis. Efeitos semelhantes das doses de $\mathrm{N}$ sobre o número de frutos e produtividade comercial por hectare foi descrito por Azambuja et al. (2015), na cultura da abobrinha "Caserta".

Dentre as hortaliças o tomateiro é uma espécie que necessita de uma alta demanda de fertilizantes, Alves et al. (2016), por sua vez observaram que o uso de insumos é necessário para a obtenção de maior produtividade comercial e total para cv. Santa Clara.

No trabalho proposto por Almeida et al. (2015), o sistema Viçosa que avaliou a eficiência agronômica e econômica de um novo sistema para o cultivo de tomateiro, proporcionou um rendimento de 109,6 t ha ${ }^{-1}$. Delazari (2014), trabalhando com lâminas de irrigação e doses de adubação obteve uma produtividade total de
$122,9 \mathrm{t} \mathrm{ha}^{-1}$ e produtividade comercial de $111,5 \mathrm{t}$ $\mathrm{ha}^{-1}$. Assim, as produtividades alcançadas no presente trabalho não fogem as médias observadas em outros trabalhos e a campo.

\section{Conclusões}

A aplicação do gel hidroretentor não influenciou na produção do tomateiro de mesa cv. Santy. O fator doses de nitrogênio proporcionou um aumento na maioria das características avaliadas, sendo observado decréscimo nos resultados quando a dosagem é excedida.

\section{Agradecimentos}

A Fundação de Amparo à Pesquisa do Estado de Goiás (FAEPG) pela concessão da bolsa.

\section{Referências}

ALMEIDA, V. S.; SILVA, D. J. H. da; GOMES, C. N.; ANTÔNIO, A. C.; MOURA, A. D.; LIMA A. L. R. Sistema Viçosa para o cultivo de 
tomateiro. Horticultura Brasileira, v.33, n.1, p. 74-79, 2015. http://dx.doi.org/10.1590/S0102$\underline{053620150000100012}$

ALMEIDA RF. 2011. Adubação Nitrogenada De Tomateiros. Revista Verde de Agroecologia e Desenvolvimento Sustentável, v.6, n.5, p. 25-30, 2011.

ALVES, G. K. E. B.; SIMÕES, A. C.; FERREIRA, R. L.; NETO, S. E. A. Produtividade de tomate orgânico cultivado em diferentes ambientes e níveis de insumos. Revista Verde de Agroecologia e Desenvolvimento Sustentável, v.11, p. 44-50, 2016. https://doi.org/10.18378/rvads.v11i4.3964

AZAMBUJA, L. O.; BENETT, C. G. S.; BENETT, K. S. S.; COSTA, E. Produtividade da abobrinha 'Caserta'em função do nitrogênio e gel hidroretentor. Científica, v.43, n.4, p. 353-358, $2015 . \quad$ http://dx.doi.org/10.15361/1984$\underline{5529.2015 v 43 n 4 p 353-358}$

ANDRIOLO, J. L.; ROSS, T. D.; WITTER, M. Crescimento, desenvolvimento e produtividade do tomateiro cultivado em substrato com três concentrações de nitrogênio na solução nutritiva. Ciência Rural, v.34, n.5, p. 1451-1457, $2004 . \quad$ http://dx.doi.org/10.1590/s0103$\underline{84782004000500019}$

DE MAMANN, A. T. W.; MANTAI, R. D.; BREZOLIN, A. P.; SCREMIN, O. B.; REGINATTO, D. C.; DA SILVA, J. A. G. A tecnologia de hidrogel à eficiência de uso de nitrogênio para o trigo no brasil com emprego de lógica fuzzy na simulação da produtividade. Salão do Conhecimento, v.2, n.2, p. 1-7 2016.

https://www.publicacoeseventos.unijui.edu.br/in dex.php/salaoconhecimento/article/view/6972

DELAZARI, F. T. Produção e qualidade de frutos do tomateiro no sistema Viçosa de tutoramento em função do estado hídrico-nutricional. Viçosa: Universidade Federal de Viçosa, 2014. 57 p.

ERTEK, A.; ERDAL, I.; YILMAZ, H. I.; SENYIGIT, U. Water and nitrogen application levels for the optimum tomato yield and water use efficiency. Journal of Agricultural Science and Technology, v.14, n.4, p. 889-902, 2012. http://journals-

old.modares.ac.ir/article 4861.html.
FANDI, M.; MUHTASEB, J.; HUSSEIN, M. Effect of $\mathrm{N}, \mathrm{P}, \mathrm{K}$ concentrations on yield and fruit quality of tomato (Solanum lycopersicum L.) in tuff culture. Journal of Central European Agriculture, v.11, n.2, p. 179-184, 2010.

FELIPPE, D.; NAVROSKI, C. M.; SAMPIETRO, J. A.; FRIGOTTO, T.; ALBUQUERQUE, J. A.; MOTA, C. S.; PEREIRA, M. O. Efeito do hidrogel no crescimento de mudas de eucaliptos benthamii submetidas a diferentes frequências de irrigação. Floresta, v.46, n.2, p. 215-225, 2016. http://dx.doi.org/10.5380/rf.v46i2.43920

FIDELIS, R. R.; LOPES, M. B. S.; MARTINEZ, R. A. S.; MARQUES, K. R.; AGUIAR, R. W. S.; VELOSO, D. A. Influence of hydrogel use on soybean cultivation hydrical stress. Bioscience Journal, v.34, n.5, p. 1219-1224, 2018.

http://www.seer.ufu.br/index.php/biosciencejou rnal/article/view/39470/24209. 29 Jan. 2019.

JAIN, N. K.; MEENA, H. N.; BHADURI D. Improvement in productivity, water-use efficiency, and soil nutrient dynamics of summer peanut (Arachis hypogaea L.) through Use of Polythene Mulch, Hydrogel, and Nutrient Management. Communications in Soil Science and Plant Analysis, v.48, n.5, p. 549-564, 2017. https://Doi:10.1080/00103624.2016.1269792

LOPES, N. F.; LIMA, M. G. S. Fisiologia da produção. Viçosa: Universidade Federal de Viçosa, 2015. 492 p.

LOPES, W. A. R.; NEGREIROS, M. Z.; DOMBROSKI, J. L. D; RODRIGUES, G. S. O.; SOARES, A. M.; ARAÚJO, A. P. Análise do crescimento de tomate 'SM-16' cultivado sob diferentes coberturas de solo. Horticultura Brasileira, v.29, n.4, p. 554561, 2011. http://dx.doi.org/10.1590/S0102$\underline{05362011000400019}$

MAROUELLI, W. A.; SOUZA, R. B.; BRAGA, M. B.; SILVA, W. L. Evaluation of sources, doses and application schedules of nitrogen on dripirrigated tomato. Horticultura Brasileira, v.32, n.3, p. 327-335, 2014.

http://dx.doi.org/10.1590/S0102-

$\underline{05362014000300015}$

MOREIRA, R. A.; RAMOS, J. D.; CRUZ, M. C. M.; VILLAR, L.; HAFLE, O. M. Efeito de doses de polímero hidroabsorvente no enraizamento de estacas de amoreira. Revista Agrarian, v.3, n.8, p. 
133-139, 2010.

http://ojs.ufgd.edu.br/index.php/agrarian/article Liew/913

NAGEL, P. L.; MACHADO, M. M. Doses de nitrogênio em cobertura em duas cultivares de abobrinha no município de AquidauanaMS. Revista Brasileira de Ciências Agrárias, v.6, n.3, p. 447-451, 2011.

http://DOI:10.5039/agraria.v6i3a1127

NICK, C.; BORÉM, A. Melhoramento de hortaliças. Viçosa: Universidade Federal de Viçosa, 2016. 427 p.

PORTO, J. S.; COSTA, R. Q.; REBOUÇAS, T. N. H.; LEMOS, O. L.; LUZ, J. M. Q.; AMORIM, Y. F. Índice SPAD e crescimento do tomateiro em função de diferentes fontes e doses de nitrogênio. Scientia Plena, v.10, n.11, p. 1-8, 2014.

https://www.scientiaplena.org.br/sp/article/view $\lcm{2041}$

RIBEIRO, A. C.; GUIMARÃES, P. T. G.; ALVAREZ, V. $H$. Recomendações para o uso de corretivos e fertilizantes em Minas Gerais: 5a aproximação. Comissão de fertilidade do solo do estado de Minas Gerais, 1999. 359 p.

SINGH, I.; VERMA, R. R.; SRIVASTAVA, T. K. Growth, yield, irrigation water use efficiency, juice quality and economics of sugarcane in pusa hydrogel application under different irrigation scheduling. Sugar Tech, v.20, n.1, p. 29-35, 2018. https://doi.org/10.1007/s12355-017-0515-9

SOARES, A. G.; FREITAS, D. D. G. C.; ROCHA, M. C.; FERREIRA, J. C. S.; OLIVEIRA, G. R. L. Caracterização físico-química, nutricional e instrumental de quatro acessos de tomate italiano (Lycopersicum esculentum Mill) do tipo 'Heirloom'produzido sob manejo orgânico para elaboração de polpa concentrada. Alimentação e Nutrição, v.22, n.4, p. 649-656, 2011.

https://core.ac.uk/download/pdf/45505365.pdf

ZEIST, A. R.; RESENDE, J. T. V.; SILVA, I. F. L.; OLIVEIRA, J. R. F.; FARIA, C. M. D. R.; GIACOBBO, C. L. Agronomic characteristics of tomato plant cultivar Santa Cruz Kada grafted on species of the genus Solanum. Horticultura Brasileira, v.35, n.3, p. 419-424, 2017.
ZEIST, A. R.; RESENDE, J. T. V.; FARIA, M. V.; GABRIEL, A.; ADRIANO, E.; LIMA FILHO, R. B. Photosynthetic characteristics in species and interspecific hybrids of tomato. Horticultura Brasileira, v. 36, n.3, p. 352-360, 2018. http://dx.doi.org/10.1590/s0102-053620180313 